\title{
Implementing geriatric programmes of excellence in Adelaide, Australia
}

\author{
Renuka Visvanathan $\mathrm{PhD}$
}

\begin{abstract}
The health system in Australia is grappling with how best to provide health care to older people in conditions of reduced inpatient beds and an ageing population. Health system managers favour programmes that result in reduced length of hospital stay. We report our hospital's experience in developing geriatric programmes of excellence that are based on comprehensive geriatric assessment and across the continuum of care, coupled with built environment, teaching, and research. Between 2007 and 2012, the programmes contributed to a 2-day reduction in acute length of stay for patients aged 80 years and older at the hospital. This translated to 8070 bed days or 22 beds saved per year.
\end{abstract}

\begin{abstract}
Adelaide Geriatrics Training and Research with Aged Care Centre, School of Medicine, Faculty of Health and Medical Sciences, University of Adelaide and Aged \& Extended Care Services, The Queen Elizabeth Hospital, Central Adelaide Local Health Network, South Australia, Australia
\end{abstract}

Correspondence to: Prof Renuka Visvanathan, Level 8B, Aged \& Extended Care Services, The Queen Elizabeth Hospital, 28 Woodville Road, Woodville South, SA 5011, Australia. Email: renuka.visvanathan@adelaide.edu.au

\section{INTRODUCTION}

Like many other developed countries experiencing population ageing, Australia is faced with increased health costs arising from the impact of chronic diseases and geriatric syndromes. It is important that health systems are designed to meet the needs of the increasing number of older people in whom frailty and geriatric syndromes are common. ${ }^{1}$

Comprehensive Geriatric Assessment (CGA) is a detailed assessment of an older person's medical, psychosocial, functional, and environmental resources and problems across acute, sub-acute, community, and nursing home settings. ${ }^{2}$ Strategies are then implemented either by clinical services (i.e. inpatient services or longer-term ambulatory follow-up) or in collaboration with other primary or secondary care providers (i.e. consultation services in and out of hospitals) with regular review and refinement of care plans until specific, measured, agreed, realistic, and time-based goals are achieved. Extended ambulatory or case management may be needed in addition to inpatient services. ${ }^{2}$ CGA may save health costs by reducing hospital readmissions and lowering the need for longer-term nursing home care. ${ }^{3,4}$ Nonetheless, further translational research is needed to determine its cost-effectiveness. ${ }^{1}$

We report our hospital's experience in developing geriatric programmes of excellence that are CGAbased and across the continuum of care, coupled with built environment, teaching, and research. In Australia, community care to older people is primarily provided through general practitioners, aged care service providers, local government, and other primary care providers (e.g. community pharmacist, allied health practitioners). Outside the hospital, private specialist consultation can be accessed following referral from general practitioners. The specialist ambulatory consultation fees may be met by the Medicare system coupled with an out-ofpocket charge.

\section{IMPLEMENTING GERIATRIC PROGRAMMES OF EXCELLENCE}

The Queen Elizabeth Hospital is a 300-bed teaching hospital for approximately 240,000 people in the western suburbs of Adelaide. In 2014, 17\% of the South Australian population were aged 65 years or older, of whom about one-third were aged 80 years or older.5 Many of the population are of lower socioeconomic status and from culturally and linguistically diverse backgrounds, making health care delivery more challenging.

In Australia in 2009, there were approximately 84.2 residential care places, 17.9 community care packages, and 3.0 subacute beds per 1000 persons 
aged 70 years or older. ${ }^{6}$ In South Australia prior to 2009, there was no inpatient Geriatric Evaluation and Management unit. Before 2007, our hospital provided very few geriatric and ambulatory services. A request for geriatric medicine consultation was often generated after a prolonged admission in another medical or surgical unit. For the small acute inpatient geriatric service, many patients were managed as outliers in medical and surgical wards, as long-stay patients taken over from other units for social care management despite the evidence that care outcome is poor when outlying is common.? There was a perception by primary care providers that the best way to access specialist geriatrician service was to refer patients to the emergency department. This was in part due to insufficient private geriatricians in the region. The lack of access to sub-acute care services could have possibly contributed to premature placement to residential care and therefore access block (delayed placement in residential aged care beds). The geriatric system in and out of hospital was poorly integrated. There was also little interaction between aged care providers and general practitioners.

In 2007, the Healthy Ageing Framework and Service Improvement Plan of the Central Northern Adelaide Health Service encouraged the development and integration of community and preventive aged care programmes. The state health department announced the 2007-2016 South Australia Health Plan ${ }^{8}$ that lead to the 20092016 Health Service Framework for Older People. ${ }^{9}$ These ensured the development of regional health services from hospital to community, with a focus on CGA including restorative, rehabilitation, dementia, palliative, and psychogeriatric care.

The built environment can support earlier return to good health for inpatients. An appropriate environment may minimise inappropriate use of medications and encourage a sense of wellbeing and mobility. ${ }^{10}$ Lighting (preferably natural sunlight) is important in the management of behavioural and psychological symptoms of dementia as it reduces the use of sedatives and anti-psychotics. ${ }^{11}$ Patients in a room with a view of nature have a shorter hospital stay and require less pain medication..$^{12}$ In 2005, our hospital incorporated 'healing gardens' and biophilia principles. ${ }^{13}$ The gardens around the geriatric ward included the 'backyard garden' with a walking space and seating to provide a sanctuary and familiarity for patients with dementia (FIGURE). The 'journey garden' was designed to promote active movement and gait training. The'savannah setting' with seats in the shade enabled stress reduction and the feeling of safety. All rooms and group areas had natural lighting through large widows and glass doors. The

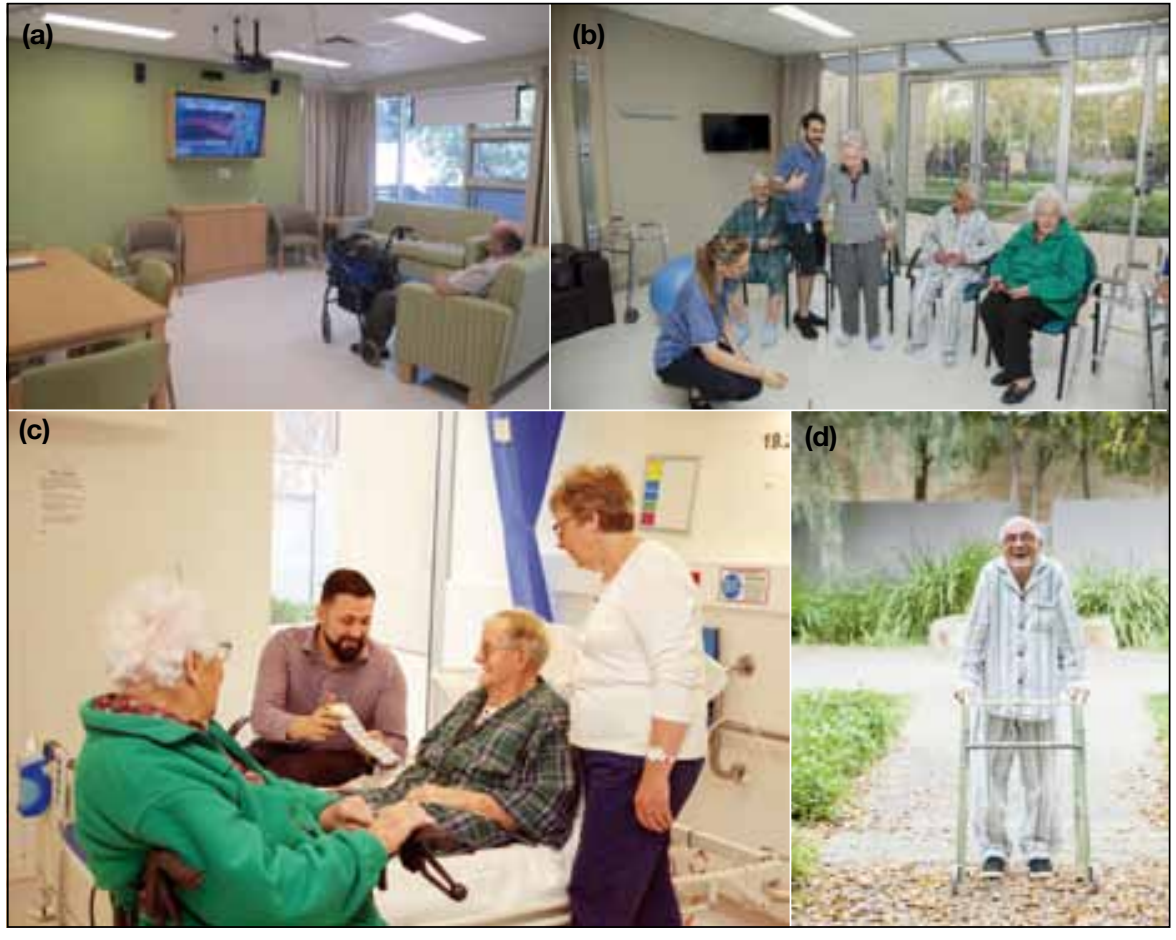

Figure. (a) The day lounge at the Geriatric Evaluation and Management Unit, (b) the therapy area looking out to the therapy garden, (c) a patient room with natural lighting and garden views, and (d) a patient walking in the therapy garden 
adjacent palliative care unit also had direct access to the gardens from single rooms. The benefit of these 'healing gardens' was derived from both active use of the space and passive views. More than $85 \%$ of respondents (staff and patients) considered the gardens to have a positive impact. ${ }^{13}$

In 2013, a new 20-bed aged mental health facility with 'healing gardens' and an allied health therapy building with large gyms and allied health treatment facilities were opened. In 2017, a further AU\$270 million investment was announced in the state budget for the development of inpatient rehabilitation services including state-of-the-art brain and spinal cord injury inpatient and ambulatory rehabilitation services as well as a revamp of our hospital emergency services and surgical facilities.

\section{IMPROVEMENT IN GERIATRIC SERVICES}

Initial improvement in geriatric services was achieved through cost-neutral initiatives that focused on building relationships, integrating existing services to achieve efficiency, and improving awareness and skills through education and training. Prior to 2008, the following strategies were initiated:

(1) Improvement in education and training for medical students and multidisciplinary staff and patient awareness of syndromes such as falls, delirium, and dementia.

(2) Development of a geriatric medicine specialist training programme from 2006.

(3) Progressive development of academic programmes including teaching and research to raise the profile of the service and contribute to knowledge translation. ${ }^{14-18}$

(4) Strengthening of relationships with rehabilitation, palliative, and older people's mental health services. A partnership was formed between adult psychiatry, aged mental health, and geriatrics services to reduce the waiting time of psychogeriatric inpatients in the emergency department.

(5) Strengthening of relationships with general practice and existing aged care providers in the region.

(6) Implementation of protocols for care including better management of delirium and dementia in older inpatients.

(7) Stronger involvement of geriatricians in the
Aged Care Assessment programme. ${ }^{19}$

(8) Increasing staff, student, and community awareness of the importance of advanced care planning through the Respecting Patient's Choices programme.

Between 2008 and 2012, the following services were applied:

(9) A community nursing programme interfacing with general practice, the royal district nursing service, and our hospital was recognised for its innovation and effectiveness. ${ }^{20}$

(10) The growth of geriatrician-led outpatient and domiciliary services from $<200$ occasions of care in the 2007/2008 financial year to 1045 occasions of care in the 2011/2012. A regional falls programme was recognised with multiple awards.

(11) Better integration of our geriatric services with the Transition Care Programme, ${ }^{21}$ which provides up to 16 weeks post-acute goalorientated, short-term restorative care to enable older patients and their families to make longterm arrangements for care. ${ }^{22}$ This programme can be delivered in homes or residential aged care facilities. The number of packages available has grown over time.

(12) Implementation of pro-active liaison services to the acute medical unit and orthopaedic service (similar to the Older Persons Assessment and Liaison service in the United Kingdom) to screen and assess all general medical patients aged 80 years and older and all hip fracture patients. There was strengthening of geriatric consultation services in the entire hospital. ${ }^{23}$

(13) Implementation of a higher acuity inpatient Geriatric Evaluation and Management unit to enable parallel delivery of both acute and rehabilitative care to achieve earlier transfer (median, $\leq 3$ days) to the ward-based unit following an emergency admission for selected patients with potential to benefit. In fact, the first Geriatric Evaluation and Management unit in South Australia was established at our hospital.

(14) Development of an orthogeriatric service and registry for hip fracture care.

(15) Implementation of standardised documentation to support CGA across the continuum of care.

(16) A focus on audit and continuous quality improvement within the service. 


\section{GERIATRIC EVALUATION AND MANAGEMENT UNIT}

In 2009, our hospital's emergency department was the third busiest in the state. One concern against the implementation of the Geriatric Evaluation and Management unit was that older patients would end up staying longer in the acute hospital because of the sub-acute model of care. We believed that the earlier 'pull' of patients following their acute journey to an appropriate care environment coupled with robust hospital consultation and liaison service (including hip fracture/orthogeriatric service) would actually shorten overall inpatient length of stay in the whole hospital for those aged 80 years and older. The liaison service ensured a dementia and delirium consultation services to the rest of the hospital. We estimated that 30 inpatient beds would be required for the catchment population but only 20 beds were commissioned. The 20-bed unit was formed through the realignment of existing acute medical beds rather than commissioning of new beds. Some additional funding was provided for allied health and geriatrician staff for the inpatient unit and geriatrician and nursing staff for the consultation and liaison service. Approximately AU\$1.1 million recurrent per year was invested to seed this change.

An acute medical unit in addition to a general medicine unit was established to improve the general medical service. This enabled the geriatric liaison service to partner with the general physicians in this unit to provide 'proactive' geriatric screening and assessment and 'pull' to the inpatient unit or ambulatory service. Some patients also received consultation and case management on a consultation basis.

Between 2007 and 2012, there was a 2-day reduction in acute length of stay in patients aged 80 years and older (TABLE). This translated to 8070 bed days or 22 beds saved per year. Assuming that the daily cost was AU $\$ 1012$ per day, the savings per year were almost AU\$8.17 million. In August 2015, the inpatient unit increased from 20 to 28 beds.

\section{DISCUSSION}

In our hospital, improvement in geriatric services was associated with reduced length of hospital stay, especially in patients aged 80 years and older. Implementation of CGA services across the continuum of care contributed to health savings.

In a meta-analysis, inpatient geriatric consultation teams have been reported to affect post-discharge mortality but not hospital readmission or length of stay. ${ }^{24}$ The inpatient and liaison services at our hospital mirror those in a United Kingdom hospital with 72 geriatric inpatient beds for 0.5 million people. ${ }^{23}$ The mean length of stay for patients aged 70 years older decreased from 12.8 days at baseline to 10.4 days in the first year and 9.1 days in the second year. $^{23}$

In another meta-analysis, compared with usual care, geriatric care (that involved one of the five principles of acute care of the elderly) resulted in reduced falls, delirium, functional decline, length of hospital stay, discharge to nursing home, and costs..$^{25}$ The five principles of acute care of the elderly include care activities to prevent functional decline, frequent medical review, involvement of physiotherapy and occupational therapy to initiate rehabilitation, early discharge planning, and an age-friendly environment. Inpatient rehabilitation for geriatric patients has also been reported to reduce mortality and admission to nursing homes and improve function, but it's cost-effectiveness remains unclear. ${ }^{26}$ Our hospital's Geriatric Evaluation and Management unit enabled

TABLE

Acute length of stay by age-groups between 2007 and 2012 (excluding patients awaiting nursing home or mental health patients)

\begin{tabular}{lcccccc}
\hline Age-group (years) & \multicolumn{7}{c}{ Acute length of stay (days) } \\
\cline { 2 - 7 } & 2007 & 2008 & 2009 & 2010 & 2011 & 2012 \\
\hline $80+$ & 9.1 & 8.42 & 7.53 & 6.73 & 6.93 & 7.03 \\
$65-79$ & 7.58 & 7.61 & 7.25 & 6.62 & 6.75 & 6.74 \\
$<65$ & 5.11 & 5.53 & 4.95 & 4.74 & 4.68 & 4.78 \\
\hline
\end{tabular}


earlier access to rehabilitative or restorative care during hospitalisation; when appropriate, both acute and rehabilitative care can be provided in parallel rather than in series.

Geriatrician-led outpatient services allow for early intervention and reduce the need for hospitalisation and readmission. Outpatient and domiciliary services should be viewed as a consultation service to general practice, meeting the needs of the out-of-hospital sector.

There were limitations to this observational study. Not all changes were accounted for and thus cause and effect could not be determined. A randomised controlled trial would be costly and difficult to implement.

\section{CONCLUSION}

Improvement in geriatric services based on CGA resulted in reduced length of hospital stay and hospital readmission for people aged 80 years and older. This provides evidence to support investment in CGA systems across the continuum of care.

\section{ACKNOWLEDGMENTS}

We would like to acknowledge the support of Ms Anne-Marie Young at the Queen Elizabeth Hospital for her assistance in providing hospital data.

\section{REFERENCES}

1. Stuck AE, Iliffe S. Comprehensive geriatric assessment for older adults. BMJ 2011;343:d6799.

2. Stuck AE, Siu AL, Wieland GD, Adams J, Rubenstein LZ. Comprehensive geriatric assessment: a meta-analysis of controlled trials. Lancet 1993;342:1032-6.

3. Ellis G, Whitehead MA, Robinson D, O'Neill D, Langhorne P. Comprehensive geriatric assessment for older adults admitted to hospital: meta-analysis of randomised controlled trials. BMJ 2011;343:d6553.

4. Stuck AE, Aronow HU, Steiner A, et al. A trial of annual in-home comprehensive geriatric assessments for elderly people living in the community. N Engl J Med 1995;333:1184-9.

5. Social health atlas of Australia: Medicare local (December 2014). Available from: http://phidu.torrens.edu.au/data-archive/shaaust/2008- 2014/phidu_data_2014_ml_aust.zip. Accessed June 2017.

6. Giles LC, Halbert JA, Gray LC, Cameron ID, Crotty M. The distribution of health services for older people in Australia: where does transition care fit? Aust Health Rev 2009;33:572-82.
7. Stowell A, Claret PG, Sebbane M, et al. Hospital out-lying through lack of beds and its impact on care and patient outcome. Scand J Trauma Resusc Emerg Med 2013;21:17.

8. South Australia's health care plan 2007-2016: the South Australian government's plan for health care over the next 10 years. Department of Health, Adelaide 2007, 9780730899051.

9. Health service framework for older people 2009-2016: improving health and wellbeing together. Statewide Services Strategy Division, Adelaide 2009, 9780730897637.

10. Huisman ER, Morales E, van Hoof J, Kort HS. Healing environment: a review of the impact of physical environmental factors on users. Build Environ 2012;58:70-80.

11. Wahnschaffe A, Nowozin C, Haedel S, et al. Implementation of dynamic lighting in a nursing home: impact on agitation but not on rest-activity patterns. Curr Alzheimer Res 2017;14:1076-83.

12. Ulrich RS. View through a window may influence recovery from surgery. Science 1984;224:420-1.

13. Forbes I. Using landscapes as wellness factor for patient therapy. In: Design \& Health World Congress \& Exhibition. Frankfurt: The international Academy for Design and Health; 2005:250-67.

14. Tam KL, Chandran K, Yu S, Nair S, Visvanathan R. Geriatric medicine course to senior undergraduate medical students improves attitude and self-perceived competency scores. Australas J Ageing 2014;33:E6-11.

15. Vanlint A, Tam KL, Yu S, Visvanathan R. Evaluation of the introduction of the OSCE to the fifth-year Geriatric Medicine Teaching Programme. Australas J Ageing 2016;35:285-8.

16. Visvanathan R, Silakong T, Yu S. Dedicated teaching block for undergraduate geriatric medicine improves knowledge. Australas J Ageing 2011;30:234-8.

17. Jadczak AD, Tam KL, Yu S, Visvanathan R. Medical students' perceptions of the importance of exercise and their perceived competence in prescribing exercise to older people. Australas J Ageing 2017;36:E7-13.

18. Archibald M, Kitson A, Frewin D,Visvanathan R. Transdisciplinary research in frailty: knowledge translation to inform new models of care. J Frailty Aging 2017;6:62-4.

19. Aged care assessment programme guidelines. Available from: https:// agedcare.health.gov.au/programs-services/guidelines/agedcare-assessment- and-approval-guidelines. Accessed June 2017.

20. Littleford A, Kralik D. Making a difference through integrated community care for older people. J Nurs Healthc Chronic Illn 2010;2:178-86.

21. Gray LC, Peel NM, Crotty M, Kurrle SE, Giles LC, Cameron ID. How effective are programs at managing transition from hospital to home? A case study of the Australian Transition Care Program. BMC Geriatr 2012;12:6.

22. Gray LC, Travers CM, Bartlett HP, Crotty M, Cameron ID. Transition care: will it deliver? Med J Aust 2008;188:251-3.

23. Harari D, Martin FC, Buttery A, O'Neill S, Hopper A. The older persons' assessment and liaison team 'OPAL': evaluation of comprehensive geriatric assessment in acute medical inpatients. Age Ageing 2007;36:670-5.

24. Deschodt M, Flamaing J, Haentjens P, Boonen S, Milisen K. Impact of geriatric consultation teams on clinical outcome in acute hospitals: a systematic review and meta-analysis. BMC Med 2013;11:48.

25. Fox MT, Persaud M, Maimets I, et al. Effectiveness of acute geriatric unit care using acute care for elders components: a systematic review and meta-analysis. J Am Geriatr Soc 2012;60:2237-45.

26. Bachmann S, Finger C, Huss A, Egger M, Stuck AE, Clough-Gorr KM. Inpatient rehabilitation specifically designed for geriatric patients: systematic review and meta-analysis of randomised controlled trials. BMJ 2010;340:c1718. 